\title{
Magnetic Resonance in Medicine at 30
}

The first issue of Magnetic Resonance in Medicine appeared in March 1984, which is 30 years ago this month. Despite all the remarkable changes over the years, both in our field and in publishing, the commitment by our authors and reviewers to scientific, technical, and clinical innovation and excellence has remained unchanged. In its history, the journal and the ISMRM have worked with three publishers: Academic Press, Williams \& Wilkins, and since 1999, Wiley. The journal has published approximately 9000 articles, which have been cited nearly 300,000 times. Many of the most important papers in our field have appeared on its pages, and the work presented in the journal continues to have a profound impact on the fields of medical research and medicine.

We are celebrating our journal's 30th Anniversary year in several ways. You may have already noticed the banner that appears on the cover of each issue published during 2014. In May, we will release a special, commemorative issue entitled "30 Magn Reson Med Papers That Helped Shape Our Field." We plan to make print copies of the issue available at the ISMRM Annual Meeting in Milan, and a full-issue PDF freely available online shortly thereafter.

\section{SELECTING THE 30 PAPERS}

With so many influential papers to choose from, selecting the 30 most influential papers published in Magnetic Resonance in Medicine for the commemorative issue was not an easy task. The selection process began when the current Editor-in-Chief (EIC) invited Gary Glover to chair the selection committee. Prof. Glover subsequently formed a committee comprising senior members of our Editorial Board, who are all listed as co-authors of this editorial. The committee includes Felix Wehrli, who was EIC of the journal from 1990 to 2004, and Derek Jones who is the current Chair of the Annual Program Committee and is organizing a special evening event at the ISMRM Annual meeting this year in Milan. The current EIC served as a non-voting member of the committee.

To provide an objective starting point, we generated a list of the 300 most highly cited Magnetic Resonance in Medicine papers of all time, according to Thomsen

*Correspondence to: Matt Bernstein, Mayo Clinic, 200 First Street SW, Rochester, MN 55905. E-mail: mrm@ismrm.org

Received 8 January 2014; revised 8 January 2014; accepted 9 January 2014

DOI 10.1002/mrm.25160

Published online 29 January 2014 in Wiley Online Library (wileyonlinelibrary. com).

(c) 2014 Wiley Periodicals, Inc.
Reuters' Web of Science ${ }^{\mathrm{SM}}$. The committee began deliberation with a series of teleconferences that spanned four countries and five time zones. We noted that many early concepts such as development of gradientrecalled imaging, shielded gradients, and phased array $\mathrm{RF}$ coils were crucial to the development of MR imaging and spectroscopy, but are now taken for granted and no longer recurrently cited. It was also observed that, while some fundamental concepts were not initially published in our journal (most notably, perhaps, the disclosure of MRI itself by Paul Lauterbur, which preceded our journal by over a decade), highly important articles were published subsequently in Magnetic Resonance in Medicine. Other considerations included closely related fields and sub-fields (e.g., ESR imaging) for which certain papers might be highly influential but would not rank as highly in the general field of magnetic resonance imaging or spectroscopy. Finally, we discussed several more recent papers that are clearly shaping our field today, but have not yet accrued a large number of citations. We decided it would be most appropriate for this commemorative issue to focus on papers that have already demonstrated influence, and to celebrate those newer papers at a future time. A list of sample topics that the committee considered highly relevant to the field, such as k-space trajectories, molecular agents, and rapid imaging, was drawn up as a guide to help us select papers that would span the breadth of Magnetic Resonance in Medicine's coverage of the field.

To obtain additional guidance and insight, the committee polled ISMRM's Full Members, who were provided the list of the 300 most-cited papers and the committee's list of sample topics. The respondents were asked to rank up to 30 choices from the list of 300, one of which could be a write-in paper not on the list, if desired. Responses from 152 Full Members of the ISMRM were recorded and used as a weighting in the committee's selection process. In addition, the committee received and considered several personal emails from ISMRM members with further comments.

The final selection proceeded by teleconference and email. Our guidance included the metrics of total number of citations (overall impact), number of citations per year since publication (enduring character), votes and comments from the ISMRM membership, coverage of the field, and the personal experience and opinions of the committee members. Some committee members' own articles came under consideration in the final selection; in each such case those members were recused from the discussion and voting about their paper. While the selection process was subjective, all the final selections were made with the unanimous consent of the voting members. The process, which began at the ISMRM's Annual 
Meeting in Salt Lake City, Utah, concluded by the end of September 2013.

\section{GALA CELEBRATION PLANNED FOR MILAN}

To celebrate the "30 Magn Reson Med Papers That Helped Shape Our Field" the Annual Meeting Program Committee has planned a special event in Milan, Italy. This event, generously hosted by Wiley, will be held at the convention center on Wednesday evening, 15 May 2014, immediately after the Business Meeting.

During the evening, the 30 papers we selected will be revealed, and attendees will receive a copy of the commemorative issue. They will also be able to meet some of the authors over light refreshments. Perhaps attendees will learn about the genesis of these influential ideas and the authors' perspective on their impact.

\section{THE NEXT 30 YEARS}

It remains an exciting time for our field, and the journal remains strong. The richness of our field and the creativity of the ISMRM membership and Magnetic Resonance in Medicine's authors continue to disprove those skeptics who believe that surely all the important advances in MR have already been made. No one knows what the next 30 years will hold, but if it is only half as exciting and as important as the previous 30, our field will continue to thrive. With this commemorative issue of Magnetic Resonance in Medicine, let's take a few moments to reflect on our remarkable past, before we get back to helping shape our future.

\section{Gary H. Glover}

Director, Radiological Sciences Laboratory

Department of Radiology

Stanford University

Stanford, California

\section{Derek K. Jones}

Cardiff University Brain Research Imaging Centre (CUBRIC)

School of Psychology

Cardiff University

Cardiff, United Kingdom

\section{Jens Frahm}

Biomedizinische NMR Forschungs GmbH am MaxPlanck-Institut für biophysikalische Chemie Göttingen, Germany

\section{R. Mark. Henkelman}

Imaging and Bioengineering Research

Sunnybrook and Women's College Health Sciences Centre

Toronto, Ontario, Canada

Jürgen Hennig

Department of Radiology

Medical Physics

University Medical Center Freiburg

Freiburg, Germany

Andrew A. Maudsley

Department of Radiology

University of Miami Miller School of Medicine

Miami, Florida

Stephen J. Riederer

MR Research Laboratory

Department of Radiology

Mayo Clinic

Rochester, Minnesota

Felix W. Wehrli

Laboratory of Structural NMR Imaging

Department of Radiology

University of Pennsylvania

Philadelphia, Pennsylvania

Matt A. Bernstein

MR Research Laboratory

Department of Radiology

Mayo Clinic

Rochester, Minnesota

\section{ACKNOWLEDGMENT}

We thank our Managing Editor, Shannon Stepanian, for continuing support. Roberta Kravitz and Sally Moran provided invaluable assistance at the ISMRM Office in Berkeley, California. We thank our partners at Wiley, including Rich Nagurka, Jen English, and Shawn Morton for their encouragement and support for our 30th Anniversary activities. 